TITLE:

\title{
Uniparental inheritance of cpDNA and the genetic control of sexual differentiation in Chlamydomonas reinhardtii
}

\author{
$\operatorname{AUTHOR}(\mathrm{S})$ :
}

Nishimura, Yoshiki

\section{CITATION:}

Nishimura, Yoshiki. Uniparental inheritance of cpDNA and the genetic control of sexual differentiation in Chlamydomonas reinhardtii. Journal of plant research 2010, 123(2): 149162

ISSUE DATE:

2010-01-13

URL:

http://hdl.handle.net/2433/128860

\section{RIGHT:}

The original publication is available at www.springerlink.com; この論文 は出版社版でありません。引用の際には出版社版をご確認ご利用くだ さい。; This is not the published version. Please cite only the published version. 


\title{
JPR symposium -- Kuroiwa Project
}

Uniparental inheritance of cpDNA and the genetic control of sexual differentiation in Chlamydomonas reinhardtii

Yoshiki Nishimura ${ }^{1,2}$

${ }^{1}$ Department of Botany, Graduate School of Sciences, Kyoto University, Oiwake-cho, Kakyo-ku, Kyoto 606-8502, Japan

${ }^{2}$ PRESTO, JST, 4-1-8 Honcho Kawaguchi, Saitama, Japan

Tel: $+81-75-753-4147$

Fax: $+81-75-753-4257$

e-mail: yoshiki@pmg.bot.kyoto-u.ac.jp

\begin{abstract}
An intriguing feature of most eukaryotes is that chloroplast (cp) and mitochondrial (mt) genomes are inherited almost exclusively from one parent. Uniparental inheritance of $\mathrm{cp} / \mathrm{mt}$ genomes was long thought to be a passive outcome, based on the fact that eggs contain multiple numbers of organelles, while male gametes, at best, contribute only a few $\mathrm{cp} / \mathrm{mtDNA}$. However, the process is likely to be more dynamic because uniparental inheritance occurs in organisms that produce gametes of identical sizes (isogamous). In Chlamydomonas reinhardtii, the uniparental inheritance of $\mathrm{cp} / \mathrm{mt}$ genomes is achieved by a series of mating type-controlled events that actively eliminate the mating type minus (mt-) cpDNA. The method by which Chlamydomonas selectively degrades mtcpDNA has long fascinated researchers, and is the subject of this review.
\end{abstract}

\section{Key Words}

cpDNA, uniparental inheritance, chlamydomonas, sexual differentiation

\section{Introduction}

The first report on non-Mendelian inheritance appeared in 1909, just 9 years after the rediscovery of Mendel's laws. Carl Correns followed the inheritance of green, variegated, and white color patterns in reciprocal crosses of the four-o'clock (Milabilis jalapa), and observed that the seedling resembled the maternal parent in phenotype. Simultaneously, Baur found that the green and variegated patterns of the leaves were 
inherited in a biparental fashion in Pelargonium. During the time of th Correns and Baur studies Correns and Baur, however, no one knew the nature of the genetic substances that defied Mendel's law. Extensive studies over the last century, using numerous techniques, including electron microscopy, genetics, molecular biology and biochemistry, have revealed that the genetic substances are in fact genomes within chloroplasts and mitochondria (Kuroiwa 1991; Birky 1995).

Chloroplasts (cp) and mitochondria (mt) are thought to have arisen from ancestral endosymbiotic relationships between nucleated cells and free-living bacteria cyanobacteria and alpha-purple bacteria, respectively. They contain their own genomes, which are presumably vestiges from their progenitors (Gray 1992). Today, we know that $\mathrm{cp}$ and $\mathrm{mt}$ genes are transmitted to the progeny solely from the maternal parent in the diverse taxa of higher plants, ferns, mosses, algae (Kuroiwa 1991), fungi (Mitchell and Mitchell 1952; Kawano et al. 1987), and animals (Hutchison et al. 1974), including humans.

The uniparental inheritance of $\mathrm{cp} / \mathrm{mt}$ genomes was long thought to be a passive outcome based on the fact that eggs contain multiple numbers of organelles, while male gametes, at best, contribute only a few (Gyllensten et al. 1991). However, the process of uniparental inheritance is likely to be more dynamic. A classic and striking example would be the occurrence of non-Mendelian inheritance in the unicellular green algae, Chlamydomonas reinhardtii, which produces gametes of identical sizes (isogamous) (Sager 1954).

The life cycle of C.reinhardtii is exquisitely simple. There are two mating types of $C$. reinhardtii, mating type plus $\left(\mathrm{mt}^{+}\right)$and mating type minus $(\mathrm{mt}-)$, controlled by a single complex mating type loci on linkage group VI (Ferris et al. 2002). C. reinhardtii undergoes a sexual life cycle, which includes defined stages of differentiation (Figure 1). Vegetative cells differentiate into gametes under conditions of nitrogen starvation and light irradiation (Pan et al. 1996). Within minutes of being mixed, gametes of opposite mating types adhere to each other by their flagella and fuse to form zygotes. After a mandatory period of dormancy, the zygote undergoes meiosis and germination to produce four haploid progeny. More than $90 \%$ of the progeny that are formed inherit chloroplast (cp) traits, preferentially from the $\mathrm{mt}^{+}$parent, a phenomenon first described more than 50 years ago (Sager 1954). 


\section{The dawn of research on the uniparental inheritance of cpDNA.}

Sager described the inheritance patterns of two UV-induced mutations, $s r 1$ and $s r 2$. The $s r 1$ mutation confers resistance to low levels of the antibiotic streptomycin, and the $s r 2$ mutation confers resistance to high levels of streptomycin. When $s r l$ was crossed to a streptomycin sensitive strain, low levels of streptomycin resistance were inherited, following Mendel's law. In contrast, when a $\mathrm{mt}+$ parent carrying the $s r 2$ mutation was crossed to a sensitive mt- parent, all of the meiotic progeny were resistant to high levels of streptomycin. In the reciprocal cross, the meiotic progeny were all streptomycin sensitive (Sager 1954). In 1962, evidence for the existence of cpDNA came from light and electron microscopic work by Ris and Plaut (Ris and Plaut 1962). Just one year later, Sager and Ishida described the isolation of cpDNA by cesium chloride $(\mathrm{CsCl})$ density gradient centrifugation (Sager and Ishida 1963). In 1989, the $s r 2$ mutation was shown to localize within the rps 12 gene of the cp genome (Liu et al. 1989).

\section{Biochemical and molecular biological evidence for the preferential reduction of mt- cpDNA}

In 1972, one biochemical study showed that the amount of mt- cpDNA decreased relative to $\mathrm{mt}^{+} \mathrm{cpDNA}, 6-24 \mathrm{~h}$ after mating (Sager and Lane 1972). The DNA from $\mathrm{mt}+$ and mt- gametes was labeled with either ${ }^{14} \mathrm{~N}$ - or ${ }^{15} \mathrm{NH}_{4} \mathrm{Cl}$, and $\mathrm{CsCl}$ density gradient centrifugation was used to monitor the fate of nuclear DNA and cpDNA in 6- and 24-h zygotes. Six hours into zygote development, the signal representing mt- cpDNA was clearly lower than the $\mathrm{mt}+\mathrm{cpDNA}$, indicating a preferential reduction of mt- cpDNA relative to $\mathrm{mt}+$ cpDNA. In 1980, the first molecular evidence for the preferential reduction of mt- cpDNA was provided by Grant et al. (Grant et al. 1980). The authors monitored the behavior of $\mathrm{mt}+$ and $\mathrm{mt}-\mathrm{cpDNA}$, taking advantage of restriction fragment length polymorphisms (RFLPs), in a C. reinhardtii mutant strain ac-u-g-23 that carries two small deletions in its chloroplast DNA. The authors found that both the deletions in cpDNA and the non-photosynthetic phenotype were uniparentally inherited.

\section{Active digestion of mt- cp nucleoids observed by fluorescent microscopy}

The 203-kb chloroplast genome of $C$. reinhardtii (Maul et al. 2002) is present at $\sim 80-100$ copies per cell, and is organized into 5-10 DNA-protein complexes, which are called chloroplast nucleoids (Kuroiwa et al. 1981). In 1982, Kuroiwa et al. found that 
DAPI (dsDNA specific fluorochrome, 4',6-diamidino-2-phenylindole)-stained mt- cp nucleoids disappeared preferentially in young zygotes within $50 \mathrm{~min}$ of mating (Kuroiwa et al. 1982). In 1999, the preferential disappearance of mt- cp nucleoids was observed in a living zygote, using SYBR Green I (dsDNA specific fluorochrome that can permeate into living cells) (Figure 1) (Nishimura et al. 1999).

The interpretation of this dramatic phenomenon, however, was controversial because the preferential disappearance of fluorescent mt- $\mathrm{cp}$ nucleoids occurred well before DNA reduction was detected by biochemical or molecular biological methods (6-24 h after mating) (Sager and Lane 1972). Two primary possibilities were proposed to explain this. One possibility was that the disintegration of $\mathrm{cp}$ nucleoids might lead to the dispersion of cpDNA molecules, and the second possibility was that the rapid digestion of cpDNA molecules might lead to the disappearance of cpDNA nucleoids.

\section{Single cell analysis using the optical tweezers}

One problem in addressing this question is that the mating reaction is performed using millions of $\mathrm{mt}+$ and $\mathrm{mt}-$ gametes (Figure 2). The cell population is inevitably a heterogeneous mixture of cells, such as unmated $\mathrm{mt}+$ and $\mathrm{mt}-$ gametes, zygotes with or without mt- cp nucleoids, and exceptional meitotic zygotes (1 5\%) that do not form meitotic zygotes (Ebersold 1967). Generally, molecular and biochemical methods require large amounts of homogeneous samples for precise analyses, and any heterogeneity in the samples would confuse the results. In other words, the "personalities" of individual cells or organelles within a population would be diluted and most likely lost in the process of analyses. On the other hand, microscopy can reveal the "personalities" at the morphological level, but not at the molecular level.

For studying the condition of cpDNA molecules during the disappearance of $\mathrm{mt}-\mathrm{cp}$ nucleoids, it was necessary to collect zygotes based on the presence or absence of mtcp nucleoids, and to analyze the individual zygotes using molecular biological techniques. To achieve this, optical tweezers were employed (Figure 3). The use of optical tweezers is a novel technique for manipulating living cells or organelles under direct microscopic observation (Ashkin et al. 1987). In this study, a single zygote with or without $\mathrm{cp}$ nucleoids was collected using optical tweezers, and the presence or absence of mt- cpDNA molecules was determined by nested PCR analysis. The individual fates of $\mathrm{mt}+$ and $\mathrm{mt}-$ zygotic cpDNA were followed separately using a 
chloroplast transformant $L O 3 c$, which harbors the bacterial gene aadA (aminoglycoside adenyl transferase).

The single zygotes that were obtained with the optical tweezers were subjected to highly sensitive nested-PCR analysis for aadA (Figure 4)(Nishimura et al. 1999). When L03c $\mathrm{mt}+$ gametes were crossed with wild-type mt- gametes, aadA gene sequences were detected in all of the zygotes that were examined. On the contrary, when the $L 03 c \mathrm{mt}-$ gametes were crossed with wild-type gametes, the aadA sequences were only amplified in younger zygotes (10 and $30 \mathrm{~min}$ after zygote formation). After the fluorescent $\mathrm{mt}-\mathrm{cp}$ nucleoids disappeared, the aadA sequences were no longer detected in the zygotes ( 90 and $120 \mathrm{~min}$ after zygote formation). These results indicate that the mt- cpDNA molecules are completely digested in $10 \mathrm{~min}$, during which the $\mathrm{mt}-\mathrm{cp}$ nucleoids disappear, and also that at least one highly effective nuclease is activated in the mtchloroplast just after zygote formation. This active digestion of mt- cpDNA is probably the basis for maternal inheritance of cpDNA.

\section{Destroyer-protector model for the active digestion of mt- cpDNA}

The simplest model for the uniparental inheritance of cpDNA is that the process consists of two distinct events that are likely to occur at different stages of the life cycle: a "protection" of $\mathrm{mt}+$ cpDNA, perhaps during gametogenesis, and a "destroyer" of unprotected mt- cpDNA during early zygote development.

\section{A) Restriction -Methylation hypothesis}

In 1972, Sager and colleagues proposed that mt- cpDNA was digested by the action of restriction enzymes, whereas the $\mathrm{mt}+\mathrm{cpDNA}$ was protected by methylation - a model analogous to the bacterial restriction-methylation system (Sager and Lane 1972). Sager and colleagues rapidly accumulated convincing evidence that shows an increase in the methylation level of $\mathrm{mt}+$ cpDNA, which was detected $7 \mathrm{~h}$ after mating (Burton et al. 1979; Royer and Sager 1979; Sano et al. 1980). Furthermore, the purification of $\mathrm{mt}+$ gamete-specific DNA methyltransferases, with molecular weights of $60 \mathrm{kDa}$ and 20 $\mathrm{kDa}$, has been reported (Sano et al. 1981). This $\mathrm{mt}+$ gamete specific methylation event was apparently reversible, as would be expected for protection (Sano et al. 1984). The gene for the chloroplast-resident DNA methyltransferase was finally identified in 2002, and its $\mathrm{mt}+$ gamete-specific expression and chloroplast localization were confirmed 
(Nishiyama et al. 2002).

On the other hand, a series of papers from independent groups has subsequently argued that methylation of $\mathrm{mt}+$ cpDNA could not explain protection adequately. Bolen et al. isolated a nuclear mutant mel that constitutively methylates cpDNA at a higher level in both $\mathrm{mt}+$ and mt- cells (Bolen et al. 1982). When mel gametes were used for crosses, normal uniparental inheritance patterns were observed, inconsistent with the restriction-methylation hypothesis. In 1984, Feng and Chiang presented evidence that treatment of cells with the methylation inhibitors, L-Ethionine and 5-azacytidine, resulted in a hypomethylation of gamete cpDNA (Feng and Chiang 1984). The hypomethylation of cpDNA had no effect on the uniparental inheritance of cpDNA, which was also inconsistent with the restriction-methylation hypothesis.

In 2001, Umen and Goodenough reported that 5-aza-2'-deoxycytidine did alter the inheritance pattern of cpDNA (Umen and Goodenough 2001). The authors did not observe destruction of hypomethylated $\mathrm{mt}+\mathrm{cpDNA}$, as a simple restriction-methylation hypothesis would predict, but instead observed that $\mathrm{mt}+$ cpDNA persisted until zygote germination, at which point it failed to replicate at normal levels. The authors proposed that germination is the critical time-point at which unmethylated, or damaged cpDNA, is finally destroyed. According to their discussion, Feng and Chiang (1984) failed to observe the effects of the inhibitors because they were added just prior to gametogenesis or mating in their experiments. Umen and Goodenough presumed that the inhibitor treatment in their experiments might have been too short to disturb critical methylation patterns. In Umen's experiment, the cells were grown on agar plates supplemented with inhibitors, which should have altered the methylation of the $\mathrm{cp}$ genomes effectively, although the methylation status of nuclear genes may also have been affected.

In 2004, Nishiyama et al. expressed chloroplast-resident methyltransferase ectopically in mt- cells, and crossed the cells to normal $\mathrm{mt}+$ cells (Nishiyama et al. 2004). The frequency of paternal or biparental transmission of cpDNA increased from $5 \sim 10 \%$ (in a wild type cross) to $\sim 23 \%$. This observation indicates that the protection of $\mathrm{mt}+\mathrm{cpDNA}$ cannot be explained solely by the methylation status of cpDNA, although it is possible that methylation may play a role in guaranteeing the strict uniparental inheritance, such as by enhancing the replication of $\mathrm{mt}+\mathrm{cpDNA}$. 


\section{B) Nuclease C}

One possible explanation for the active digestion of mt- cpDNA is that a nuclease is either activated or synthesized during early zygote development, and subsequently degrades the unprotected mt- cpDNA. Kuroiwa and colleagues set out to identify nucleases that are specifically required for the uniparental inheritance of cpDNA. Rather than using whole cell extracts from vegetative cells, Ogawa and Kuroiwa began with zygotes. They identified a class of $\mathrm{Ca}^{2+}$-dependent nucleases that displayed both endoand exo-nucleolytic activity. The extracts were composed of six small polypeptides, which were collectively designated as nuclease C (Ogawa and Kuroiwa 1985b). Because $\mathrm{Ca}^{2+}$ is required for the preferential digestion of mt- cpDNA (Kuroiwa 1985), it was proposed that some of these nucleases might engage in preferential digestion. However, no differences in nuclease activity were detected between the gametes and zygotes, and it was not possible to identify the nucleases responsible for cpDNA digestion (Ogawa and Kuroiwa 1985b). On the other hand, an experiment with partially purified Nuclease $\mathrm{C}$ provided an important insight into the protection of $\mathrm{mt}+\mathrm{cpDNA}$. Ogawa and Kuroiwa showed that the $\mathrm{mt}+\mathrm{cp}$ nucleoids of mature $\mathrm{mt}+$ gametes were resistant to Nuclease $\mathrm{C}$, whereas the cp nucleoids of mature mt- gametes and vegetative cells of both mating types were rapidly digested by treatment with Nuclease C (Ogawa and Kuroiwa 1985a). This result indicates that $\mathrm{Ca}^{2+}$-dependent nucleases may be responsible for preferential digestion, and that $\mathrm{mt}+\mathrm{cpDNA}$ is specifically protected during $\mathrm{mt}+$ gametogenesis by unknown mechanisms.

One problem of the previous studies on Nuclease $\mathrm{C}$ might be that nuclease activities were studied only by SDS-PAGE / in gelo assay, which may artificially activate or inactivate nucleases. To eliminate this problem, a native-PAGE was employed, and changes in the nuclease activities were reexamined in $\mathrm{mt}+$ and $\mathrm{mt}-$ chloroplasts that were isolated from zygotes 30, 60, and 90 min after mating (Nishimura et al. 2002). As shown in Figure 5, a novel nuclease activity was identified that only appeared in the mtzygotic chloroplasts; this nuclease activity would be a good candidate to act as a driving force for the active degradation of mt- cpDNA. Research to identify the gene that encodes this nuclease activity is now underway. Based on these observations, our current model is summarized in Figure 6.

C) A surveillance system may monitor the cpDNA copy number in uniparental 
inheritance

Further insight into how the cpDNA content of the $\mathrm{mt}+$ parent influences uniparental inheritance has been obtained from studies on the mat 3 mutant. The mat 3 mutation was isolated in a screen to identify $\mathrm{mt}^{+}-$-specific genes required for the uniparental inheritance of cpDNA (Gillham et al. 1987). The mat3 mutation is linked to the $\mathrm{mt}+$ locus, and when present in the $\mathrm{mt}+$ parent, prevents the elimination of mt- cpDNA in zygotes, while it has no effect on mtDNA inheritance. The size of mat 3 vegetative cells and gametes are much smaller than those of the WT, and contain a limited amount of cpDNA (Armbrust et al. 1995).

When chlamydomonas cells are treated with 5-fluorodeoxyuridine (FdUrd), a specific inhibitor of cpDNA replication, the amount of cpDNA is reduced dramatically (Wurtz et al. 1979). When FdUrd-treated mt+ gametes are mated to WT mt- gametes, a higher frequency of biparental inheritance is observed.

Based on these two observations, the mat 3 mutation is hypothesized to prevent the degradation of mt- cpDNA as a secondary consequence of the reduced amount of $\mathrm{mt}+$ cpDNA (Armbrust et al. 1995). Armbrust et al. proposed that chlamydomonas might be able to count the intact cpDNA copy number, and inhibit mt- cpDNA elimination when the amount of $\mathrm{mt}+\mathrm{cpDNA}$ is below a threshold level.

The causative gene for the mat 3 phenotype has been identified as a retinoblastoma protein homolog (Umen and Goodenough 2001). The retinoblastoma protein is the prototype tumor suppressor, and plays a key role in regulating cell cycle entry and cell size (Buttitta and Edgar 2007). Intriguingly, a retinoblastoma related protein was identified as a gender specific gene that is likely be related to sexual differentiation in Volvox carteri (Kianianmomeni et al. 2008).

\section{Active digestion of male cp/mtDNA as one of the universal mechanisms of uniparental inheritance in eukaryotes}

Active digestion of $\mathrm{mt}$ nucleoids is observed not only in chlamydomonas but also in animals. Shortly after a mouse egg is fertilized, male mtDNA can be PCR amplified from egg cytoplasm, whereas later male mtDNA cannot be detected (Kaneda et al. 1995). 
In 2006, using Japanese medaka (Oryzias latipes) as a model system, mt nucleoids were visualized during spermatogenesis and fertilization by vital double staining with the DNA-specific fluorochrome SYBR Green I and a mitochondrial membrane-specific dye MitoTracker (Nishimura et al. 2006). The number of mt nucleoids was reduced dramatically during spermatogenesis. Upon fertilization, rapid disappearance of sperm mt nucleoids was observed in apparently intact mitochondria. Furthermore, the nested PCR analysis using a single sperm, with or without $\mathrm{mt}$ nucleoids, collected by the optical tweezer revealed that mtDNA is degraded along with the disappearance of $\mathrm{mt}$ nucleoids (Figure 7) (Nishimura et al. 2006). In addition to the examples above, active digestion of uniparental mt (cp) DNA has been observed in various species, including higher plants (Nagata et al. 1999; Liu et al. 2004), algae (Kuroiwa 1991), and true slime mold (Moriyama and Kawano 2003), indicating that active digestion of male $\mathrm{cp} / \mathrm{mtDNA}$ is one of the universal mechanisms to achieve uniparental inheritance in eukaryotes. Intriguingly, studies with other mammals show that this phenomenon involves the ubiquitin-dependent proteolysis of mitochondrial membrane proteins (Sutovsky et al. 1999; Thompson et al. 2003)

\section{Genetic control of sexual differentiation and uniparental inheritance in $C$. reinhardtii}

In 1967, Sager and Ramanis showed that brief UV irradiation of $\mathrm{mt}+$ gametes just prior to mating prevents the selective elimination of mt- cpDNA in zygotes, and thus enhances the frequency of biparental inheritance of cpDNA. The same treatment of mtgametes had no effect on the transmission of cpDNA (Sager and Ramanis 1967). On the other hand, if the UV irradiated $\mathrm{mt}+$ gametes were allowed to recover in light prior to mating, the frequency of exceptional zygotes decreased. Sager and Ramanis hypothesized that UV irradiation blocked the synthesis of a $\mathrm{mt}+$ gamete specific gene product that is necessary for the elimination of mt- cpDNA in zygotes. In this section, our current understanding of the molecular mechanism that control gametogenesis, and zygote maturation is summarized (Figure 8).

A) Genetic control of gametogenesis

Upon the removal of nitrogen, vegetative cells undergo two critical programs 
(Goodenough et al. 2007). First, the cells acclimate to nitrogen starvation through a variety of metabolic changes, including up-regulation of proteins required for transport and reduction of nitrate (Fernandez and Galvan 2008), extra-cellular nitrogen-scavenging enzymes (Vallon et al. 1993), and a reduction in photosynthetic activity through a selective destabilization of $b_{6} / f$ complexes (Bulte and Wollman 1992). Secondly, the cells express a gamete differentiation program, which include the formation of sex-specific agglutinin proteins, responsible for flagellar adhesion (Adair et al. 1982), and the formation of sex-specific mating structures (Detmers et al. 1983; Ferris et al. 1996). The blue light is thought to be important to complete gametogenesis (Huang and Beck 2003; Huang et al. 2004). Although a large number of gamete-specific genes have been reported so far (von Gromoff and Beck 1993; Merchan et al. 2001; Abe et al. 2004), only some of these genes are summarized in this review.

Mating type is under the control of the MT locus, a region of suppressed recombination that spans nearly $\sim 1 \mathrm{Mb}$ on linkage group VI (Ebersold 1967; Ferris et al. 2002). The central rearranged domain $(\mathrm{R})$ is flanked by centromere proximal $(\mathrm{C})$ and telomere proximal $(\mathrm{T})$ sequences.

It has been shown that when a $\mathrm{mt}+/ \mathrm{mt}$ - heterozygous vegetative diploid is nitrogen -starved, the diploid mates as a mt-, which demonstrates the dominance of mt- over $\mathrm{mt}+$ (Ebersold 1967). The MID gene, unique to region f of the mt- locus, is responsible for the minus dominance (Ferris and Goodenough 1997). The MID protein has a bZIP motif, and is related to the RWP-RK family that also includes NIT2, a transcription factor involved in nitrate uptake and metabolism (Camargo et al. 2007). Cells expressing a MID gene differentiate as mt-; a loss of function mutation or a deletion of MID prevents the cells from differentiating as minus, and instead results in a "pseudo-plus" phenotype, indicating that $M I D$ encodes a transcription factor that both turns on mt- specific genes and turns off mt+ specific genes (Ferris and Goodenough 1997). Recently, a MID ortholog has been identified in the oogamous volvocacean Pleodorina starrii (Nozaki et al. 2006) and the isogamous Gonium pectorale (Hamaji et al. 2008), indicating the significance of the MID gene in the evolutionary process of sex determination.

The autosomal $S A D 1$ gene encodes the minus agglutinin at the mt- mating locus, and the autosomal (LGVIII) gene $S A G 1$ encodes the plus agglutinin, whose expression is probably under the control of the MID gene. The agglutinins are enormous fibrous hydroxyproline-rich glycoproteins (HRGPs) that are responsible for the flagellar 
adhesion between $\mathrm{mt}+$ and $\mathrm{mt}-$ gametes (Ferris et al. 2005). The initial adhesion of the flagella of $\mathrm{mt}+$ and $\mathrm{mt}$ - gametes triggers a complex signaling pathway, which includes a protein tyrosine kinase (Wang and Snell 2003), a cGMP-dependent protein kinase (Wang et al. 2006), adenylyl cyclase(s) (Saito et al. 1993), and an increase in intracellular cAMP. Both of the gametes shed their cell walls through the action of a metalloprotease (Kubo et al. 2001). Then, the mating structures located on the apical cell membranes between the two flagella of both gametes are activated (Detmers et al. 1983). Continued flagellar adhesion brings the activated mating structures close to each other. The $\mathrm{mt}+$ gamete-specific protein FUS1, present on the plasma membrane of the mating structure, is essential for pre-fusion attachment between the plus and minus mating structures (Misamore et al. 2003). Complete cell fusion requires an additional factor, GCS1 (GENERATIVE CELL SPECIFIC) / HAP2, on the mt- mating type structure, which is conserved ubiquitously in algae, higher plants, and protists (Mori et al. 2006; Liu et al. 2008).

After the cell fusion, two homeoproteins, GSP1 (Kurvari et al. 1998) and GSM1, contributed by the $\mathrm{mt}+$ and $\mathrm{mt}$ - gametes respectively, physically interact and translocate from the cytosol to the nucleus upon zygote formation, initiating the zygote development program (Lee et al. 2008). Intriguingly, GSP1/GSM1 dyads are similar and functionally related to the KNOX/BELL dyads that regulate meristem specification in land plants. This prompted Lee et al. to propose that combinatorial homeoprotein-based transcriptional control may have originated in a sexual context, and enabled the evolution of land-plant body plans (Lee et al. 2008).

B) Genetic control of zygote maturation

In 1988, Nakamura et al. showed that the expression of at least six zygote polypeptides was inhibited when the $\mathrm{mt}+$, but not the $\mathrm{mt}-$, parent was exposed to brief UV irradiation (Nakamura et al. 1988). This experiment showed, for the first time, that UV treatment of $\mathrm{mt}+$ gametes could inhibit the expression of a subset of zygote-specific genes.

Several independent attempts to identify zygote-specific genes have been made (Ferris and Goodenough 1987; Wegener and Beck 1991; Uchida et al. 1993; Kubo et al. 2008). The list of the zygote-specific genes that has been obtained has become an excellent resource for insight into the molecular mechanism of zygote formation and maturation. B-1) EZY1 (Early Zygote 1): 
Ezyl is tandemly repeated 7-8 times at both the $\mathrm{mt}+$ and mt- mating loci, and the repeats are transcribed immediately upon zygote formation (Armbrust et al. 1993). Ezyl was found in a differential screen for zygote-specific genes (Ferris and Goodenough 1987). The EZY1 protein localizes specifically to both $\mathrm{mt}+$ and $\mathrm{mt}-\mathrm{cp}$ nucleoids. Brief irradiation of $\mathrm{mt}+$ gametes prior to mating inhibited the transcription of ezyl, whereas the same treatment of mt- gametes had no effect on ezyl transcription. Polypeptide 4 was originally identified by Nakamura et al. as a zygote polypeptide whose expression is UV-sensitive (Nakamura et al. 1988), and likely corresponds to EZY1. Therefore, based on this evidence, the ezyl gene has been hypothesized to be involved in the selective elimination of mt- cpDNA. However, the detailed function of EZY1 is still unknown.

\section{B-2)ZYS 1, 3}

Zys 1 is a pair of invertedly repeated genes $(z y s 1 A$ and zys $1 B)$ that are $98 \%$ identical, and encode $22 \mathrm{kDa}$ polypeptide with a Zn finger motif (Uchida et al. 1993; Uchida et al. 1999). The gene product localizes to the cell nucleus, and gene expression begins at 10 min and lasts until approximately $3 \mathrm{~h}$ after mating. Importantly, when $\mathrm{mt}+$ gametes are UV-irradiated, accumulation of the ZYS1 protein is considerably reduced, suggesting its involvement in the uniparental inheritance of cpDNA.

Zys3 was identified as an early zygote-specific gene by Uchida et al. (Uchida et al. 1993), and was then carefully characterized by Kuriyama et al. (Kuriyama et al. 1999). The ZYS3 bears two types of protein-protein interaction motifs: the ankyrin repeats and the WW domain. ZYS3 localizes to the ER from $10 \mathrm{~min}$ to $6 \mathrm{~h}$ after mating. Kuriyama et al. speculated that ZYS3 might regulate the ER functions in the processing, sorting and targeting of rigid, zygote-specific cell wall materials, and/or sticky extracellular matrices. In an extensive macro-array analysis for zygote-specific genes (Kubo et al. 2008), a gene (EZY9) which is highly similar to ZYS3 was identified, implying that there is an interaction between these two gene products.

B-3) Zygote cell wall genes

After 2-3 $\mathrm{h}$ of mating, the zygotes proceed to develop new cell walls that are denser and thicker than those of vegetative cells, and that are insoluble in chaotropes and SDS. Eventually, the zygotes become adhesive so that if they are maintained in liquid, they adhere in flat sheets, forming a structure called a "pellicle". During this process, Chlamydomonas cells switch back and forth between two differential developmental 
programs expressed by vegetative cells and by gamete/zygotic cells, which features hydroxyproline rich glyocproteins (HGRPs), which are the major proteins of the cell wall. The zygote-specific genes that are involved in this process are ZSP1 (Woessner and Goodenough 1989) and ZSP2 (Suzuki et al. 2000). Other HRGPs (GAS28, 30) and glycoproteins (GAS31) are expressed in the late phase of gametogenesis and are further up-regulated in zygotes (Hoffmann and Beck 2005). Kubo et al. identified candidate zygotic genes that may be related to cell wall synthesis thorough sugar metabolism (EZY4: UDP-glucose 4-epimerase like protein, EZY11: UDP-glucose protein: protein trans glycosylase, EZY12: UDP-glucose 6-dehydrogenase, EZY16: cell wall protein pherophorin-C15) (Kubo et al. 2008). Since ezy11, 12, and 16 were up-regulated without the cell fusion, the authors proposed that these genes may be involved in cell wall synthesis of both vegetative / gamete cells and zygotes.

\section{Conclusion}

In this review, our current mechanistic model for the uniparental inheritance of cpDNA, and the molecular mechanisms controlling the sexual differentiation of Chlamydomonas, have been summarized with a historical overview of previous studies. Despite the abundance of information, our understanding of the molecular mechanism of uniparental inheritance is still at a very preliminary stage. For the next several decades, it will be of crucial interest to understand the regulatory mechanism of uniparental inheritance in the context of the complex molecular system of sexual differentiation of Chlamydomonas.

\section{Acknowledgments}

I would like to thank Dr. Tsuneyoshi Kuroiwa, Hirofumi Uchimiya, and Toshiharu Shikanai for their thoughtful suggestions, generous support and encouragements. I would also like to thank Dr. Takeaki Kubo for his helpful discussions. This work was supported by Grants from PRESTO (Precursory Research for Embruonic Science and Technology), JSPS Grant-in-Aid for Young Scientists (B 19770050) and Kyoto University Step-Up Grant-in Aid for Young Scientists to Y.N.

\section{References}


Abe J, Kubo T, Takagi Y, Saito T, Miura K, Fukuzawa H, Matsuda Y (2004) The transcriptional program of synchronous gametogenesis in Chlamydomonas reinhardtii. Curr Genet 46: 304-315.

Adair WS, Monk BC, Cohen R, Hwang C, Goodenough UW (1982) Sexual agglutinins from the Chlamydomonas flagellar membrane. Partial purification and characterization. J Biol Chem 257: 4593-4602.

Adair WS, Steinmetz SA, Mattson DM, Goodenough UW, Heuser JE (1987) Nucleated assembly of Chlamydomonas and Volvox cell walls. J Cell Biol 105: 2373-2382.

Armbrust EV, Ferris PJ, Goodenough UW (1993) A mating type-linked gene cluster expressed in Chlamydomonas zygotes participates in the uniparental inheritance of the chloroplast genome. Ce11 74: 801-811.

Armbrust EV, Ibrahim A, Goodenough UW (1995) A mating type-linked mutation that disrupts the uniparental inheritance of chloroplast DNA also disrupts cell-size control in Chlamydomonas. Mol Biol Cell 6: 1807-1818.

Ashkin A, Dziedzic JM, Yamane T (1987) Optical trapping and manipulation of single cells using infrared laser beams. Nature 330: 769-771.

Birky CW, Jr. (1995) Uniparental inheritance of mitochondrial and chloroplast genes: mechanisms and evolution. Proc Nat1 Acad Sci U S A 92: 11331-11338.

Bolen PL, Grant DM, Swinton D, Boynton JE, Gillham NW (1982) Extensive methylation of chloroplast DNA by a nuclear gene mutation does not affect chloroplast gene transmission in chlamydomonas. Cel1 28: 335-343.

Bulte L, Wollman FA (1992) Evidence for a selective destabilization of an integral membrane protein, the cytochrome $b_{6} / f$ complex, during gametogenesis in Chlamydomonas reinhardtii. Eur J Biochem 204: 327-336.

Burton WG, Grabowy CT, Sager R (1979) Role of methylation in the modification and restriction of chloroplast DNA in Chlamydomonas. Proc Nat1 Acad Sci U S A 76: 1390-1394. 
Buttitta LA, Edgar BA (2007) Mechanisms controlling cell cycle exit upon terminal differentiation. Curr Opin Cell Biol 19: 697-704.

Camargo A, Llamas A, Schne11 RA, Higuera JJ, Gonzalez-Ballester D, Lefebvre, PA, Fernandez, E and Galvan, A (2007) Nitrate signaling by the regulatory gene NIT2 in Chlamydomonas. Plant Cel1 19: 3491-3503.

Detmers PA, Goodenough UW, Condeelis J (1983) Elongation of the fertilization tubule in Chlamydomonas: new observations on the core microfilaments and the effect of transient intracellular signals on their structural integrity. J Cell Biol 97: 522-532.

Ebersold WT (1967) Chlamydomonas reinhardi: heterozygous diploid strains. Science 157: 447-449.

Feng TY, Chiang KS (1984) The persistence of maternal inheritance in Chlamydomonas despite hypomethylation of chloroplast DNA induced by inhibitors. Proc Nat1 Acad Sci U S A 81: 3438-3442.

Fernandez E, Galvan A (2008) Nitrate assimilation in Chlamydomonas. Eukaryot Ce11 7: 555-559.

Ferris PJ, Goodenough UW (1987) Transcription of novel genes, including a gene linked to the mating-type locus, induced by Chlamydomonas fertilization. Mo1 Ce11 Biol 7: 2360-2366.

Ferris PJ, Goodenough UW (1997) Mating type in Chlamydomonas is specified by mid, the minus-dominance gene. Genetics 146: 859-869.

Ferris PJ, Woessner JP, Goodenough UW (1996) A sex recognition glycoprotein is encoded by the plus mating-type gene fus1 of Chlamydomonas reinhardtii. Mol Biol Cell 7: 1235-1248.

Ferris PJ, Armbrust EV, Goodenough UW (2002) Genetic structure of the mating-type locus of Chlamydomonas reinhardtii. Genetics 160: 181-200.

Ferris PJ, Waffenschmidt S, Umen JG, Lin H, Lee JH, Ishida K, Kubo T, Lau $\mathrm{J}$ and Goodenough UW (2005) Plus and minus sexual agglutinins from Chlamydomonas reinhardtii. Plant Ce11 17: 597-615.

Gillham NW, Boynton JE, Johnson AM, Burkhart BD (1987) Mating type linked mutations which disrupt the uniparental transmission of chloroplast 
genes in chlamydomonas. Genetics 115: 677-684.

Goodenough U, Lin H, Lee JH (2007) Sex determination in Chlamydomonas. Semin Cel1 Dev Biol 18: 350-361.

Grant DM, Gillham NW, Boynton JE (1980) Inheritance of chloroplast DNA in Chlamydomonas reinhardtii. Proc Nat1 Acad Sci U S A 77: 6067-6071. Gray MW (1992) The endosymbiont hypothesis revisited. Int Rev Cytol 141: $233-357$.

Gyllensten U, Wharton D, Josefsson A, Wilson AC (1991) Paternal inheritance of mitochondrial DNA in mice see comments]. Nature 352: 255-257.

Hamaji T, Ferris PJ, Coleman AW, Waffenschmidt S, Takahashi F, Nishii I, Nozaki H (2008) Identification of the minus-dominance gene ortholog in the mating-type locus of Gonium pectorale. Genetics 178: 283-294.

Hoffmann XK, Beck CF (2005) Mating-induced shedding of cell walls, removal of walls from vegetative cells, and osmotic stress induce presumed cell wall genes in Chlamydomonas. Plant Physiol 139: 999-1014.

Huang K, Beck CF (2003) Phototropin is the blue-light receptor that controls multiple steps in the sexual life cycle of the green alga Chlamydomonas reinhardtii. Proc Natl Acad Sci U S A 100: 6269-6274.

Huang K, Kunkel T, Beck CF (2004) Localization of the blue-light receptor phototropin to the flagella of the green alga Chlamydomonas reinhardtii. Mol Biol Cell 15: 3605-3614.

Hutchison CA, 3rd, Newbold JE, Potter SS, Edgel1 MH (1974) Maternal inheritance of mammalian mitochondrial DNA. Nature 251: 536-538.

Kaneda H, Hayashi J, Takahama S, Taya C, Lindahl KF, Yonekawa H (1995) Elimination of paternal mitochondrial DNA in intraspecific crosses during early mouse embryogenesis. Proc Natl Acad Sci U S A 92: $4542-4546$.

Kawano S, Anderson RW, Nanba T, Kuroiwa T (1987) Polymorphism and uniparental inheritance of mitochondrial DNA in Physarum polycephalum. J Gen Microbiol 133: 3175-3182.

Kianianmomeni A, Nematollahi G, Hallmann A (2008) A gender-specific retinoblastoma-related protein in Volvox carteri implies a role for 
the retinoblastoma protein family in sexual development. Plant Cel1 20: 2399-2419.

Kubo T, Saito T, Fukuzawa H, Matsuda Y (2001) Two tandemly-located matrix metalloprotease genes with different expression patterns in the chlamydomonas sexual cell cycle. Curr Genet 40: 136-143.

Kubo T, Abe J, Oyamada T, Ohnishi M, Fukuzawa H, Matsuda Y, Saito T (2008) Characterization of novel genes induced by sexual adhesion and gamete fusion and of their transcriptional regulation in Chlamydomonas reinhardtii. Plant Cell Physiol 49: 981-993.

Kuriyama H, Takano H, Suzuki L, Uchida H, Kawano S, Kuroiwa H, Kuroiwa T (1999) Characterization of Chlamydomonas reinhardtii zygote-specific cDNAs that encode novel proteins containing ankyrin repeats and WW domains. Plant Physiol 119: 873-884.

Kuroiwa T (1985) Mechanisms of maternal inheritance of chloroplast DNA: An active digestion hypothesis. Microbiol Sci 2: 267-270.

Kuroiwa T (1991) The replication, differentiation, and inheritance of plastids with emplasis on the concept of organelle nuclei. Int Rev Cyt1 128: 1-60.

Kuroiwa T, Suzuki T, Ogawa K, Kawano S (1981) The chloroplast nucleus: distribution, number, size, and shape, and a model for the multiplication of the chloroplast genome during chloroplast development. Plant Cel1 Physiol 22: 381-396.

Kuroiwa T, Kawano S, Nishibayashi S, Sato C (1982) Epifluorescent microscopic evidence for maternal inheritance of chloroplast DNA. Nature 298: 481-483.

Kurvari V, Grishin NV, Snell WJ (1998) A gamete-specific, sex-limited homeodomain protein in Chlamydomonas. J Cel1 Biol 143: 1971-1980.

Lee JH, Lin H, Joo S, Goodenough U (2008) Early sexual origins of homeoprotein heterodimerization and evolution of the plant KNOX/BELL family. Cel1 133: 829-840.

Liu XQ, Gillham NW, Boynton JE (1989) Chloroplast ribosomal protein gene rps12 of Chlamydomonas reinhardtii. Wild-type sequence, mutation to 
streptomycin resistance and dependence, and function in Escherichia coli. J Biol Chem 264: 16100-16108.

Liu Y, Cui H, Zhang Q, Sodmergen (2004) Divergent potentials for cytoplasmic inheritance within the genus Syringa. A new trait associated with speciogenesis. Plant Physiol 136: 2762-2770.

Liu Y, Tewari R, Ning J, Blagborough AM, Garbom S, Pei J, Grishin NV, Steele RE, Sinden RE, Snell WJ, Billker 0 (2008) The conserved plant sterility gene HAP2 functions after attachment of fusogenic membranes in Chlamydomonas and Plasmodium gametes. Genes Dev 22: 1051-1068.

Maul JE, Lilly JW, Cui L, dePamphilis CW, Miller W, Harris EH, Stern DB (2002) The Chlamydomonas reinhardtii plastid chromosome: islands of genes in a sea of repeats. Plant Cel1 14: 2659-2679.

Merchan F, van den Ende H, Fernandez E, Beck CF (2001) Low-expression genes induced by nitrogen starvation and subsequent sexual differentiation in Chlamydomonas reinhardtii, isolated by the differential display technique. Planta 213: 309-317.

Misamore MJ, Gupta S, Snel1 WJ (2003) The Chlamydomonas Fus1 protein is present on the mating type plus fusion organelle and required for a critical membrane adhesion event during fusion with minus gametes. Mol Biol Cel1 14: 2530-2542.

Mitchell MB, Mitchell HK (1952) A Case of "Maternal" Inheritance in Neurospora Crassa. Proc Nat1 Acad Sci U S A 38: 442-449.

Mori T, Kuroiwa H, Higashiyama T, Kuroiwa T (2006) GENERATIVE CELL SPECIFIC 1 is essential for angiosperm fertilization. Nat Cell Biol 8: 64-71. Moriyama Y, Kawano S (2003) Rapid, selective digestion of mitochondrial DNA in accordance with the matA hierarchy of multiallelic mating types in the mitochondrial inheritance of Physarum polycephalum. Genetics 164: 963-975.

Nagata N, Saito C, Sakai A, Kuroiwa H, Kuroiwa T (1999) The selective increase or decrease of organellar DNA in generative cells just after pollen mitosis one controls cytoplasmic inheritance. Planta 209: 
$53-65$.

Nakamura S, Sato C, Kuroiwa T (1988) Polypeptides related to preferential digestion of male chloroplast nucleoids in Chlamydomonas. Plant Sci 56: $129-136$.

Nishimura Y, Misumi 0, Matsunaga S, Higashiyama T, Yokota A, Kuroiwa T (1999) The active digestion of uniparental chloroplast DNA in a single zygote of Chlamydomonas reinhardtii is revealed by using the optical tweezer. Proc Natl Acad Sci U S A 96: 12577-12582.

Nishimura Y, Misumi 0, Kato K, Inada N, Higashiyama T, Momoyama Y, Kuroiwa $\mathrm{T}$ (2002) An $\mathrm{mt}(+)$ gamete-specific nuclease that targets $\mathrm{mt}(-)$ chloroplasts during sexual reproduction in $C$. reinhardtii. Genes Dev 16: 1116-1128.

Nishimura Y, Yoshinari T, Naruse K, Yamada T, Sumi K, Mitani H, Higashiyama T, Kuroiwa T (2006) Active digestion of sperm mitochondrial DNA in single living sperm revealed by optical tweezers. Proc Natl Acad Sci U S A 103: 1382-1387.

Nishiyama R, Ito M, Yamaguchi Y, Koizumi N, Sano H (2002) A chloroplast-resident DNA methyltransferase is responsible for hypermethylation of chloroplast genes in Chlamydomonas maternal gametes. Proc Nat1 Acad Sci U S A 99: 5925-5930.

Nishiyama R, Wada Y, Mibu M, Yamaguchi Y, Shimogawara K, Sano H (2004) Role of a nonselective de novo DNA methyltransferase in maternal inheritance of chloroplast genes in the green alga, Chlamydomonas reinhardtii. Genetics 168: 809-816.

Nozaki H, Mori T, Misumi 0, Matsunaga S, Kuroiwa T (2006) Males evolved from the dominant isogametic mating type. Curr Biol 16: R1018-1020.

Ogawa K, Kuroiwa T (1985a) Destruction of chloroplast nuclei of the male gamete by calcium and nuclease $\mathrm{C}$ in a cell model of Chlamydomonas reinhardtii. Plant Cel1 Physiol 26: 481-491.

Ogawa K, Kuroiwa T (1985b) Nuclease C polymorphism of calcium-dependent nucleases in Chlamydomonas reinhardtii. Plant Cell Physiol 26: 481-489. 
Pan JM, Haring MA, Beck CF (1996) Dissection of the Blue-Light-Dependent Signal-Transduction Pathway Involved in Gametic Differentiation of Chlamydomonas reinhardtii. Plant Physiol 112: 303-309.

Ris H, Plaut W (1962) Ultrastructure of DNA-containing areas in the chloroplast of Chlamydomonas. J Cel1 Biol 13: 383-391.

Royer HD, Sager R (1979) Methylation of chloroplast DNAs in the life cycle of Chlamydomonas. Proc Natl Acad Sci U S A 76: 5794-5798.

Sager R (1954) Mendelian and Non-Mendelian Inheritance of Streptomycin Resistance in Chlamydomonas Reinhardi. Proc Natl Acad Sci U S A 40: 356-363.

Sager R, Ishida MR (1963) Chloroplast DNA in Chlamydomonas. Proc Nat1 Acad Sci U S A 50: 725-730.

Sager R, Ramanis Z (1967) Biparental inheritance of nonchromosomal genes induced by ultraviolet irradiation. Proc Natl Acad Sci U S A 58: 931-937.

Sager R, Lane D (1972) Molecular basis of maternal inheritance. Proc Nat1 Acad Sci U S A 69: 2410-2413.

Saito T, Small L, Goodenough UW (1993) Activation of adenylyl cyclase in Chlamydomonas reinhardtii by adhesion and by heat. J Cell Biol 122: $137-147$.

Sano H, Royer HD, Sager R (1980) Identification of 5-methylcytosine in DNA fragments immobilized on nitrocellulose paper. Proc Natl Acad Sci U S A 77: 3581-3585.

Sano H, Grabowy C, Sager R (1981) Differential activity of DNA methyltransferase in the life cycle of Chlamydomonas reinhardi. Proc Natl Acad Sci U S A 78: 3118-3122.

Sano H, Grabowy C, Sager R (1984) Loss of chloroplast DNA methylation during dedifferentiation of Chlamydomonas reinhardi gametes. Mol Cell Biol 4: 2103-2108.

Sutovsky P, Moreno RD, Ramalho-Santos J, Dominko T, Simerly C, Schatten G (1999) Ubiquitin tag for sperm mitochondria. Nature 402: 371-372.

Suzuki L, Woessner JP, Uchida H, Kuroiwa H, Yuasa Y, Waffenschmidt S, 
Goodenough UW, Kuroiwa T (2000) A zygote-specific protein with hydroxyproline-rich glycoprotein domains and lectin-like domains involved in the assembly of the cell wall of Chlamdomonas reinhardti (chlorophyta). J Phycol 36: 571-583.

Thompson WE, Ramalho-Santos J, Sutovsky P (2003) Ubiquitination of prohibitin in mammalian sperm mitochondria: possible roles in the regulation of mitochondrial inheritance and sperm quality control. Biol Reprod 69: 254-260.

Uchida H, Kawano S, Sato N, Kuroiwa T (1993) Isolation and characterization of novel genes which are expressed during the very early stage of zygote formation in Chlamydomonas reinhardtii. Curr Genet 24: 296-300.

Uchida H, Suzuki L, Anai T, Doi K, Takano H, Yamashita H, Oka T, Kawano S, Tomizawa KI, Kawazu T, Kuroiwa H, Kuroiwa T (1999) A pair of invertedly repeated genes in Chlamydomonas reinhardtii encodes a zygote-specific protein whose expression is UV-sensitive. Curr Genet 36: $232-240$.

Umen JG, Goodenough UW (2001) Chloroplast DNA methylation and inheritance in Chlamydomonas. Genes Dev 15: 2585-2597.

Vallon 0, Bulte L, Kuras R, 0live J, Wollman FA (1993) Extensive accumulation of an extracellular L-amino-acid oxidase during gametogenesis of Chlamydomonas reinhardtii. Eur J Biochem 215: $351-360$.

Voigt J, Woestemeyer J, Frank R (2007) The chaotrope-soluble glycoprotein GP2 is a precursor of the insoluble glycoprotein framework of the Chlamydomonas cell wall. J Biol Chem 282: 30381-30392.

Voigt J, Frank R, Wostemeyer J (2009) The chaotrope-soluble glycoprotein GP1 is a constituent of the insoluble glycoprotein framework of the Chlamydomonas cell wall. FEMS Microbiol Lett 291: 209-215.

von Gromoff ED, Beck CF (1993) Genes expressed during sexual differentiation of Chlamydomonas reinhardtii. Mol Gen Genet 241: 415-421. 
Wang Q, Snell WJ (2003) Flagellar adhesion between mating type plus and mating type minus gametes activates a flagellar protein-tyrosine kinase during fertilization in Chlamydomonas. J Biol Chem 278: 32936-32942.

Wang Q, Pan J, Snell WJ (2006) Intraflagellar transport particles participate directly in cilium-generated signaling in Chlamydomonas. Cel1 125: 549-562.

Wegener D, Beck CF (1991) Identification of novel genes specifically expressed in Chlamydomonas reinhardtii zygotes. Plant Mol Biol 16: 937-946.

Woessner JP, Goodenough UW (1989) Molecular characterization of a zygote wall protein: an extensin-like molecule in Chlamydomonas reinhardtii. Plant Ce11 1: 901-911.

Wurtz EA, Sears BB, Rabert DK, Shepherd HS, Gillham NW, Boynton JE (1979) A specific increase in chloroplast gene mutations following growth of Chlamydomonas in 5-fluorodeoxyuridine. Mol Gen Genet 170: $235-242$. 

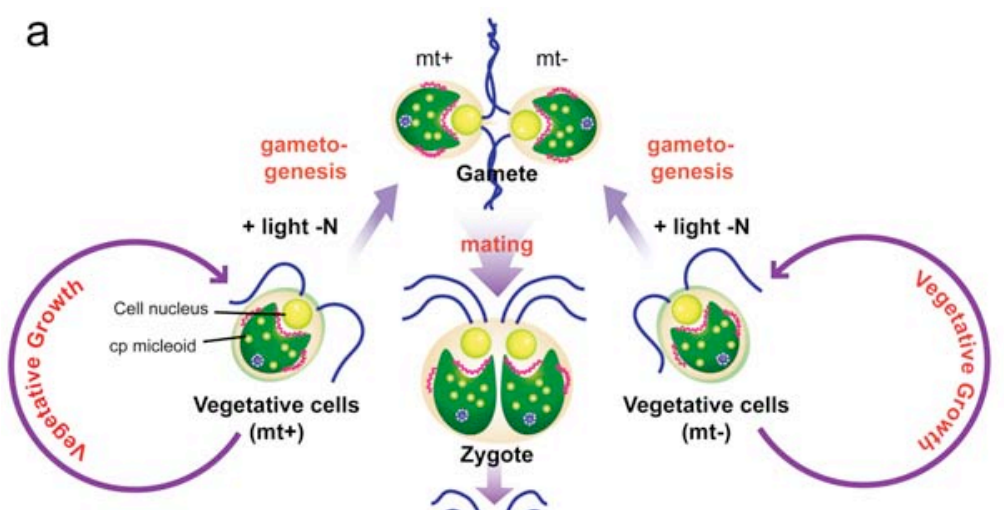

b
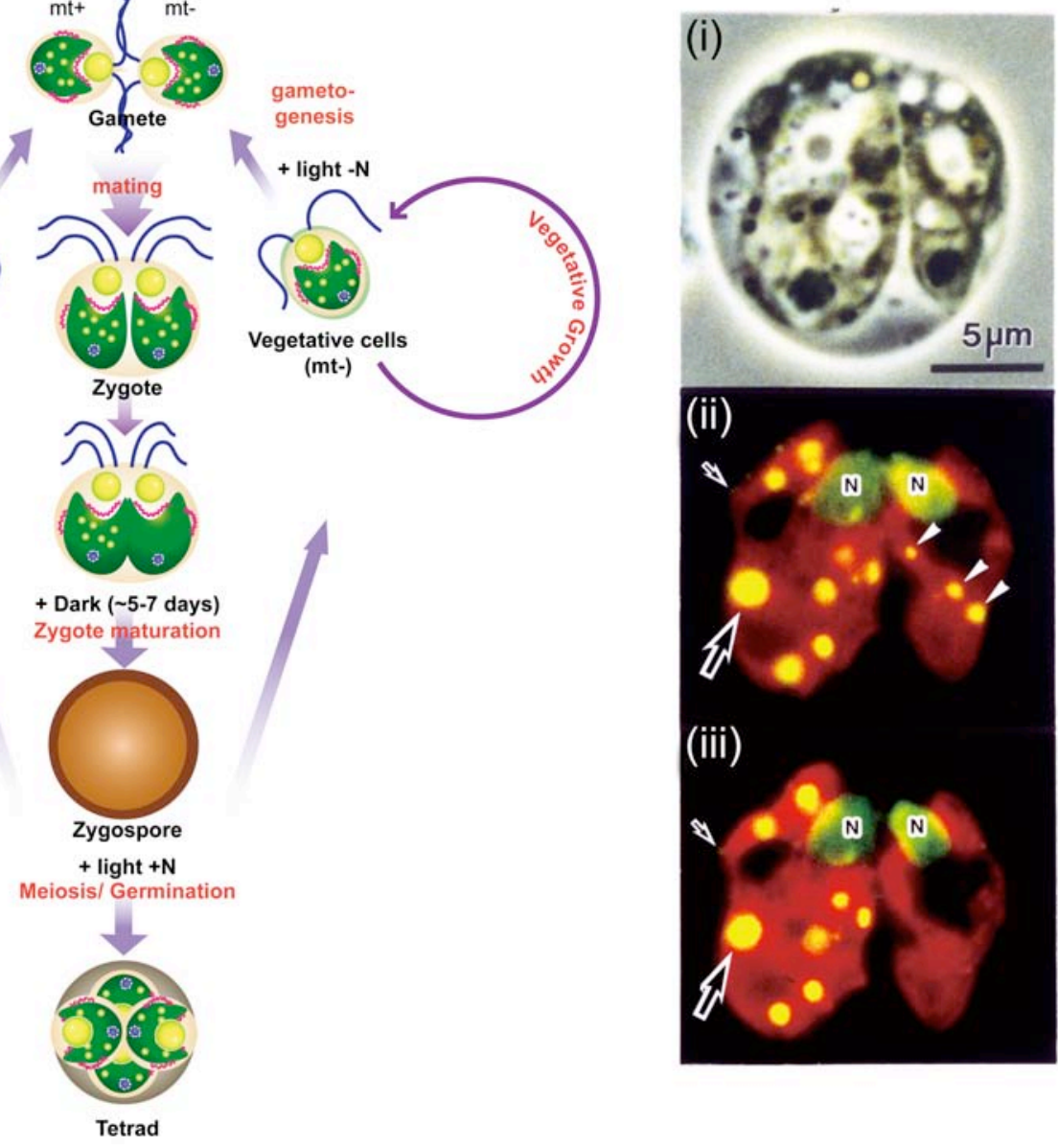

Fig. 1

(a) The sexual life cycle of Chlamydomonas reinhardtii consists primarily of four critical stages - gametogenesis, zygote formation, zygote maturation (zygospore formation), and meiosis (zygospore germination). Gametogenesis is induced by the loss of a nitrogen source and light. When gametes of opposite mating types are mixed together, flagellar adhesion triggers gamete activation that leads to the cell-cell fusion (zygote formation). Zygotes will develop into zygospores with a thick cell wall, which is a dormant stage in the life cycle. The cycle begins again when the appropriate environmental conditions stimulate the dormant zygote to undergo germination, in order to produce new haploid $\mathrm{mt}+$ and $\mathrm{mt}-$ haploid cells. During this process, cpDNA and mtDNA molecules are uniparentally inherited from $\mathrm{mt}+$ and $\mathrm{mt}-$ parents, respectively.

(b) Preferential disappearance of mt- cp nucleoids was visualized in a living zygote of C. reinhardtii. The living zygote was stained with SYBR Green I. Phase-contrast (i) and fluorescent images of an identical zygote before (ii) and after (iii) the 
preferential disappearance are shown. The mt+ (Left) and mt- (Right) chloroplasts emit red autofluorescence. The cell nucleus $(\mathrm{N})$, cp nucleoids (big fluorescent spots; large arrow), and mitochondrial nucleoids (small fluorescent spots; small arrow). The cp nucleoids in the mt- chloroplasts (ii, white arrowheads) disappeared completely within $10 \mathrm{~min}$ (ii and iii). (Nishimura et al. 1999) 


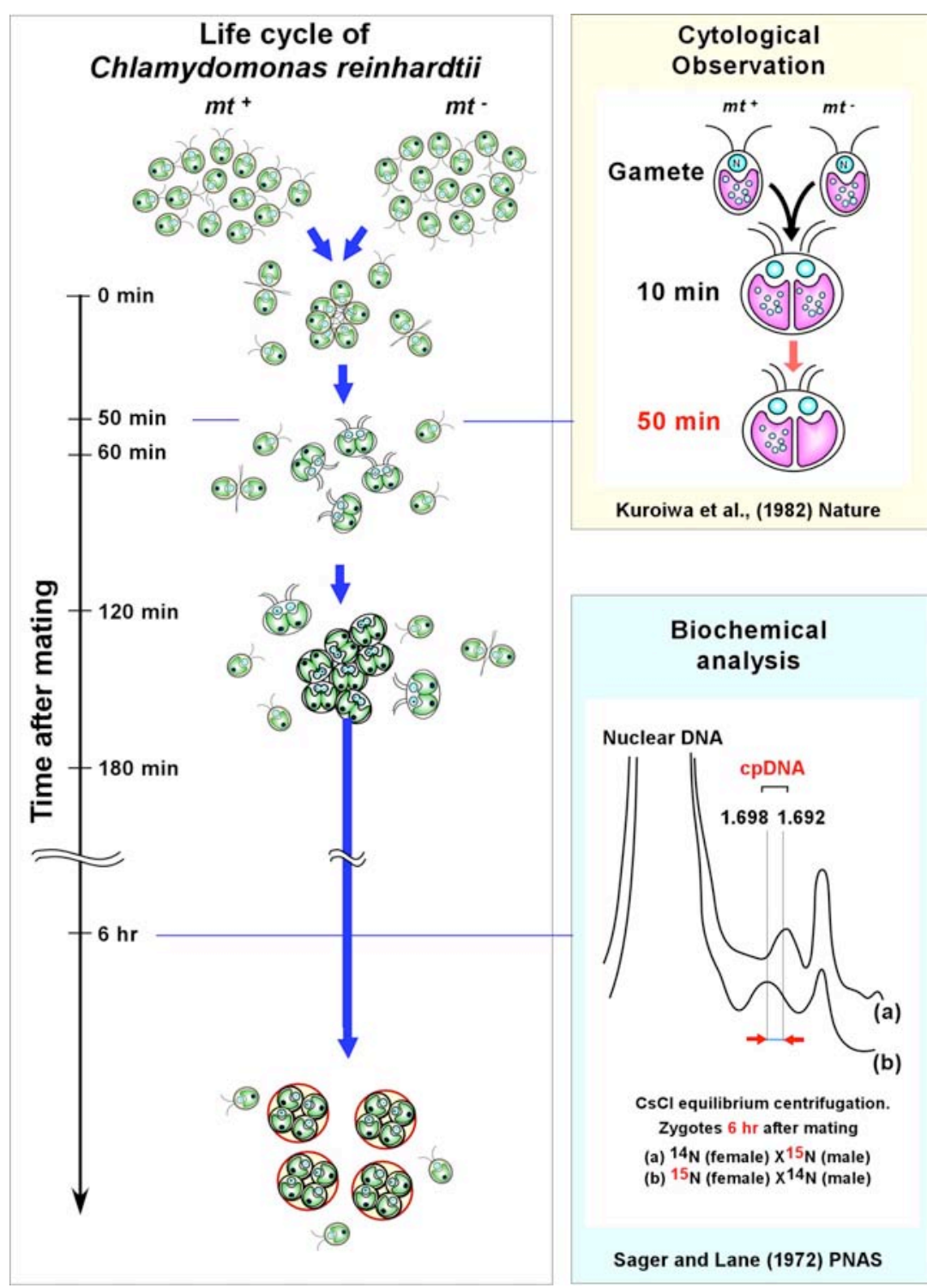

Fig. 2 The discrepancy between the preferential disappearance of mt- cp nucleoids (Cytological observation: 50 min after mating (Kuroiwa et al., 1982)) and the relative reduction of mt- cpDNA (6 24 h after mating (Sager and Lane, 1972)). Due to the time lag between these two independent observations, the interpretation of the preferential disappearance of mt- cpDNA was controversial. Two primary explanations were proposed: 1) disintegration of cp nucleoids caused diffusion of cpDNA molecules 2) destruction of the cpDNA molecule. In order to determine the correct explanation, a single zygote with or without mt- cp nucleoids must be collected for molecular analysis, since the time lag between $50 \mathrm{~min}$ and $6 \sim 24 \mathrm{~h}$ may have been caused by the heterogeneous nature of the cell population during the mating reaction. 
a
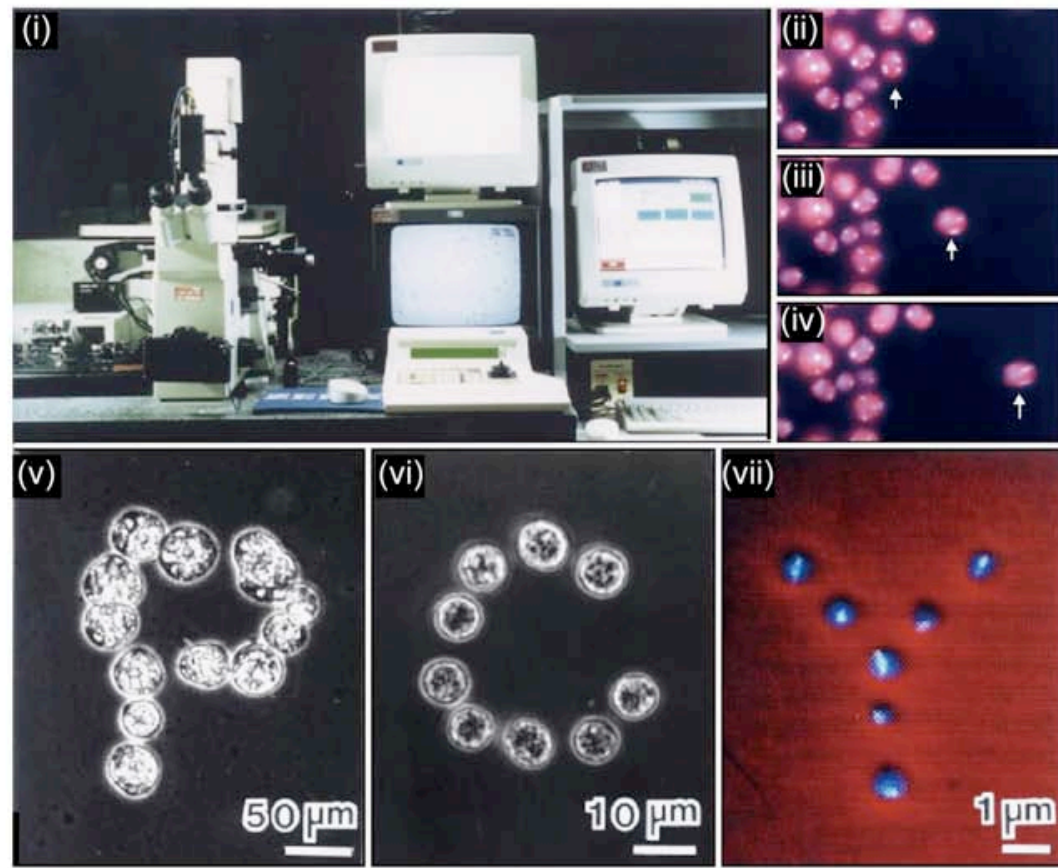

$\mathrm{b}$

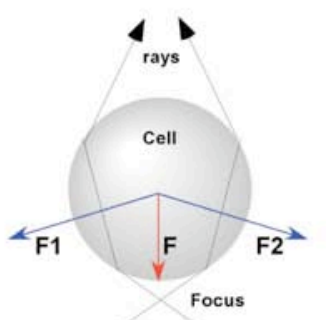

Objective Lens

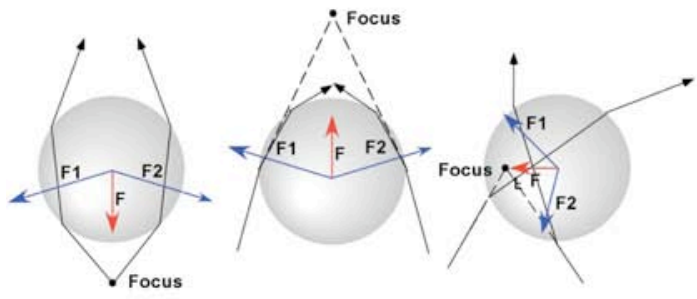

C Isolation Chamber
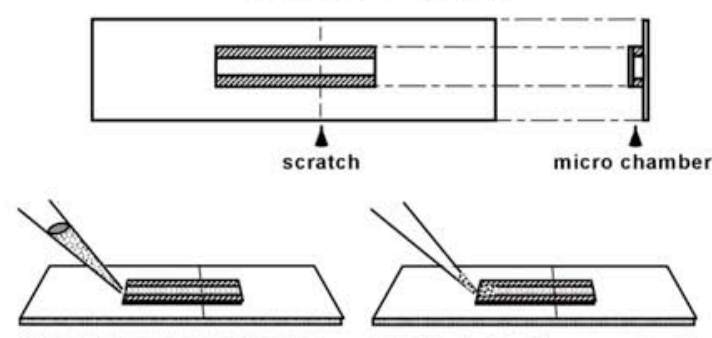

i) the microchamber is filled with sterile medium

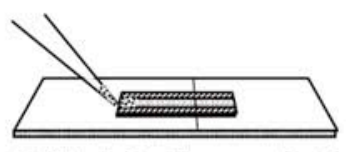

ii) $0.5 \mu \mathrm{I}$ of cell suspension is added to one end

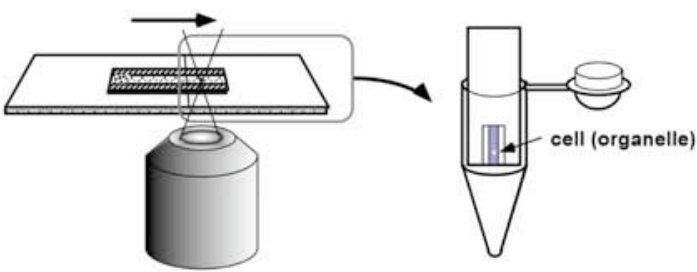

iii) the cell or organelle of iv) the isolation chamber is cut interest is separated using and placed into PCR tube the optical tweezers

\section{Fig. 3}

(a) The optical tweezer (i). By using the IR (infra-red) laser, one chlamydomonas cell in the cell population was selectively manipulated (ii-iv). BY-2 protoplasts arranged into "P" (v). Chalmydomonas cells arranged into "C" (vi). DAPI-stained 
mitochondria isolated from true slime mold were arranged into "Y" (vii).

(b) The mechanism of laser trapping. When a cell refracts the laser beam (gray sphere), the cell will receive forces (F1 and F2) from the laser beam, and the resultant force is $\mathrm{F}$ (red arrow). As the $\mathrm{F}$ is directed toward the center of the focal point, the cell is eventually trapped at the center of the laser focus.

(c) The optical isolation process and the "isolation microchamber." The microchamber is formed by separation of a large $(5 \times 30 \times 0.15 \mathrm{~mm}$, length $\times$ width $\times$ thickness $)$ and small $(9 \times 3 \times 0.15 \mathrm{~mm})$ coverslip with two thin strips of adhesive tape $(9 \times 1 \times 0.1 \mathrm{~mm})$. The inside dimensions of the chamber were $9 \times 1$ $\times 0.1 \mathrm{~mm}$. A small scratch was made on the chamber with a diamond knife. The bottoms of 5-cm diameter Petri dishes were cut out with a knife and replaced with thin, plastic film ( $\approx 100-\mu \mathrm{m}$ thick). Filter paper was cut and placed into the dishes, and roughly $200 \mu 1$ of distilled water was added dropwise to keep the inside of the dish moist. The chamber was then placed inside the dish and attached to the plastic film by using one drop of distilled water. First, the chamber was filled with sterile buffer containing $1.5 \%$ sucrose and $0.1 \%$ BSA (i). The BSA was added to prevent cells from adhering to the glass chamber. Then, $0.5 \mu 1$ of the cell suspension was carefully applied to one end of the chamber (ii). The cells were observed with a microscope, and a single cell was trapped with the optical tweezers and transferred to the opposite end of the chamber (iii). The transfer was processed automatically with a microscopic stage control system (MCU26 X, Y, Z-Axes Motor Control; Zeiss) at a velocity of $1-60 \mu \mathrm{m} / \mathrm{sec}$. When the cell moved past the scratch in the chamber, the chamber was cut immediately, and the piece containing the cell of interest was placed in a PCR tube (iv). The PCR tube was centrifuged for $5 \mathrm{sec}$ to drop the cell into the tube. (Nishimura et al. 1999) 


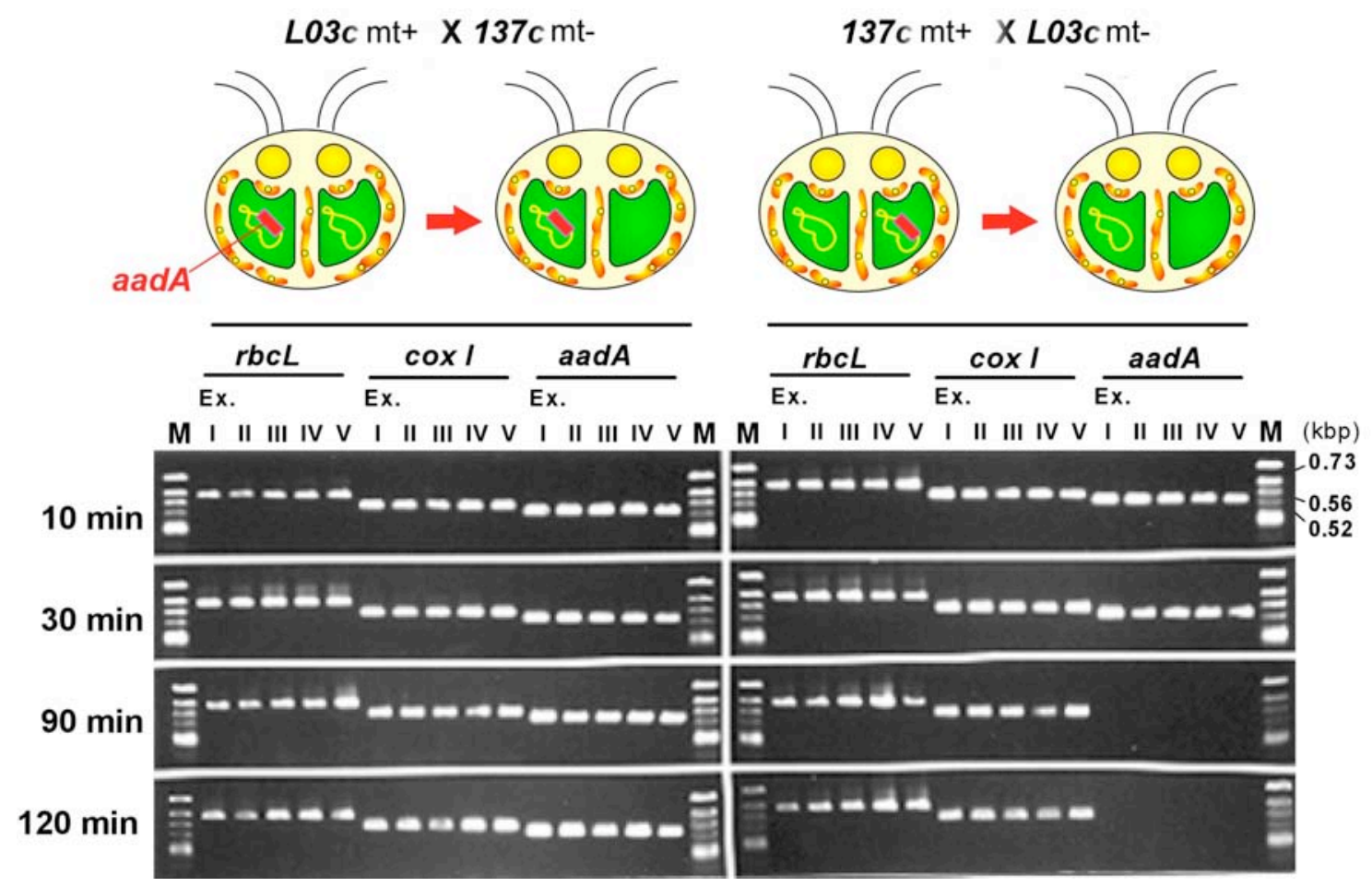

Fig. 4

Nested-PCR amplification of $r b c L$ (cpDNA), cox I (mtDNA), and aadA sequences from one optically isolated gamete or zygote 10, 30, 90, and 120 min after zygote formation. One zygote resulting from the crosses $L 03 c \mathrm{mt}^{+} \times 137 c \mathrm{mt}^{-}$or $137 c \mathrm{mt}^{-} \times L 03 c \mathrm{mt}^{-}$ was isolated by using the optical tweezers, and was then immediately subjected to nested PCR analysis. One typical zygote was isolated from each of the cell cultures 10 , 30, 90, and 120 min after mating. To ensure reproducibility, each experiment was repeated five times $(\mathrm{I}-\mathrm{V})$. The lanes marked $\mathrm{M}$ are loaded with marker. (Nishimura et al. 1999) 
a

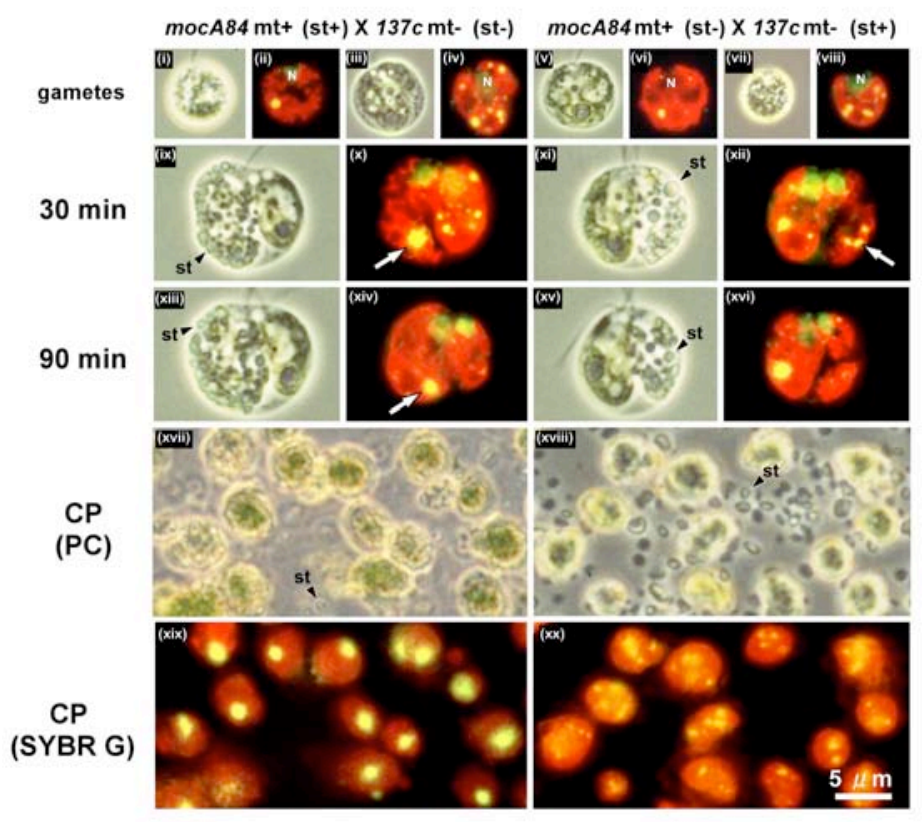

b

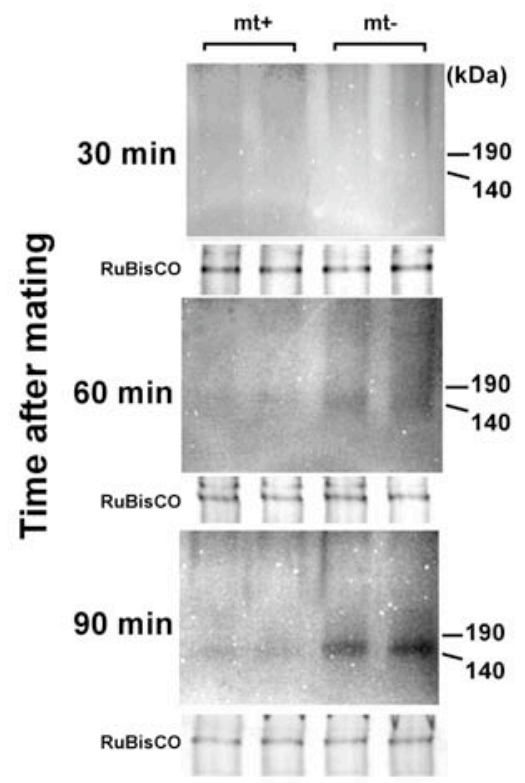

Fig. 5

(a) Phase-contrast (i, iii, v, vii, ix, xi, xiii, xv, xvii, xviii) and fluorescent (ii,iv,vi,viii,x,xii,xiv,xvi,xix,xx) images of SYBR Green I-stained gametes (mocA84 $\mathrm{mt}+[\mathrm{i}, \mathrm{ii}, \mathrm{v}, \mathrm{vi}$ ]; $137 \mathrm{cmt}$ - [iii, iv, v, vi]), zygotes (30 min [ix-xii]; $90 \mathrm{~min}$ [xiii-xvi] after mating), and $\mathrm{mt}+$ (xvii, xix) and $\mathrm{mt}$ - (xviii, $\mathrm{xx}$ ) chloroplasts isolated from zygotes at 30 min after mating. Gametes that were incubated for $10 \mathrm{~d}$ accumulated large quantities of starch granules in their chloroplasts (st+; i, ii, vii, viii), whereas gametes that were incubated for $2 \mathrm{~d}$ accumulated few starch granules (st-; iii, iv, v, vi). By crossing the two different kinds of gametes, zygotes were formed that accumulate large numbers of starch granules, only in $\mathrm{mt}+$ chloroplasts (ix, $\mathrm{x}$, xiii, xiv) or mt- chloroplasts (xi, xii, xv, xvi). The presence of a large amount of starch did not affect the active digestion of mtcpDNA (xiii-xvi). Chloroplasts containing large amounts of starch granules were isolated and selectively separated by Percoll step-gradient centrifugation. The purity of separated chloroplasts was verified by moc-type single cp nucleoid $(\mathrm{mt}+)$ or WT cp nucleoids (mt-) (xvii-xx). (St) Starch granules. (b) Comparison of $\mathrm{Ca}^{2+}$-dependent nuclease activity in $\mathrm{mt}+$ and $\mathrm{mt}-$ chloroplasts using the native-PAGE/in gelo assay. The $\mathrm{mt}+$ and $\mathrm{mt}-$ chloroplasts that were isolated from zygotes at 30,60, and $90 \mathrm{~min}$ after mating were analyzed. Experiments were repeated twice to ensure reproducibility. As a control, $\mathrm{CBB}$-stained $\mathrm{RuBisCO}$ bands are shown under each lane. (Nishimura et al. 
2002)

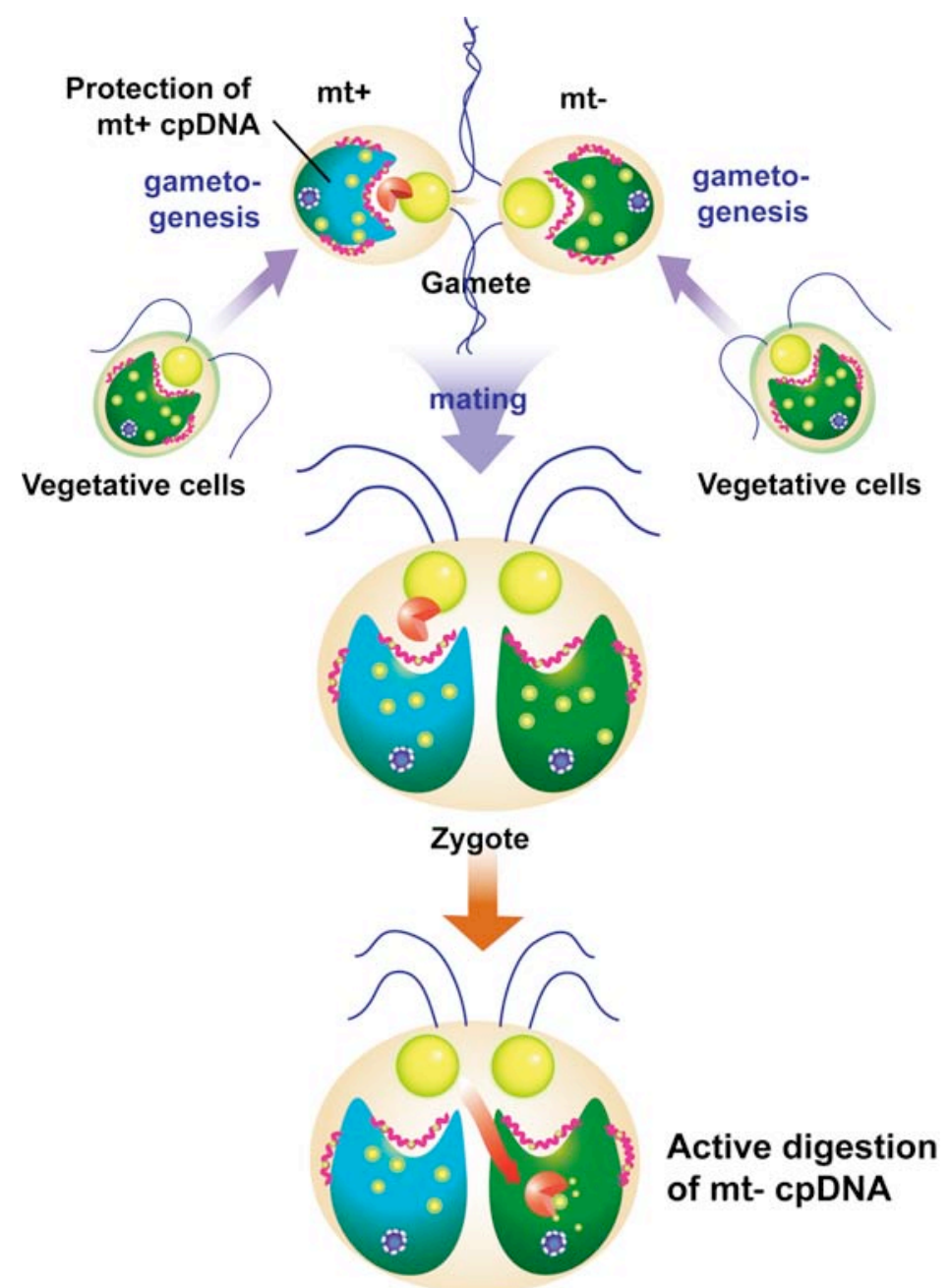

Fig. 6

A model for the molecular mechanism of uniparental inheritance in $C$. reinhardtii that is based on the active digestion of mt- cpDNA by MDN. In vegetative cells, MDN is absent or inactivated in both mating types. During gametogenesis, MDN is synthesized or activated only in $\mathrm{mt}+$ cells. At the same time, $\mathrm{mt}+\mathrm{cpDNA}$ becomes resistant to the action of MDN. During gamete fusion, MDN obtains access to unprotected mtchloroplasts and digests mt- cpDNA, leading to the uniparental inheritance of cpDNA. Several factors may mediate the successful digestion of mt- cpDNA after zygote formation: (1) entry of MDN into mt- chloroplasts; (2) efficient access of MDN to cpDNA molecules; and (3) an increase in $\mathrm{Ca}^{2+}$ inside mt- chloroplasts. Zygote-specific gene expression may be crucial to these processes. (Nishimura et al. 2002) 
a

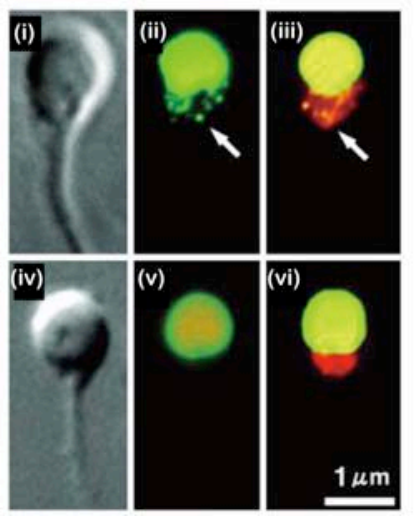

b

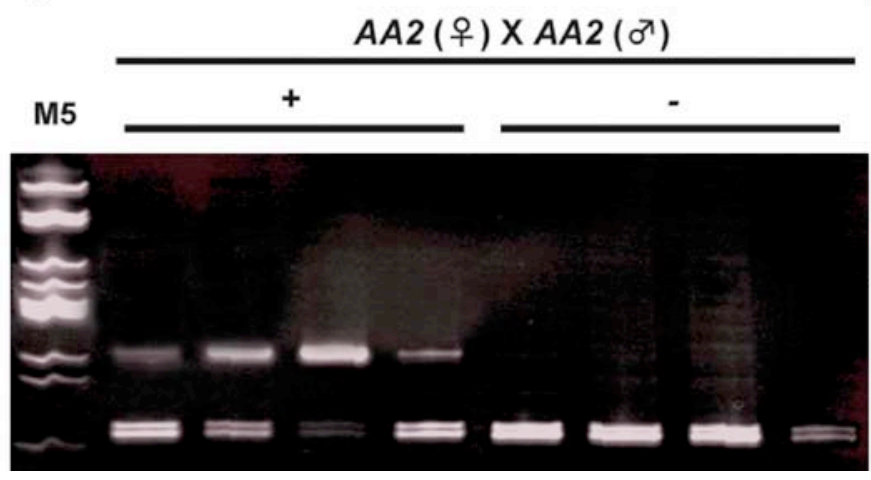

Fig. 7

Active digestion of sperm mtDNA after fertilization. (A) Phase-contrast images ( $a$ and $d$ ), SYBR green I-stained images (green) ( $b$ and $e$ ), and SYBR green I/MitoTracker CMTMRos double-stained images (red) ( $c$ and $f$ ) of sperm before $(a-c)$ and 60 min after $(d-f)$ fertilization. $a$ and $\mathrm{b}$ are the identical sperm. $d$ and $e$ are also identical. Sperm $\mathrm{mt}$ nucleoids completely disappeared $60 \mathrm{~min}$ after fertilization ( $e$ and $f$ ). The mitochondrial structure visualized by phase-contrast microscopy $(d)$ or by MitoTracker CMTMRos staining $(f)$ remained intact, even after the disappearance of fluorescent mt nucleoids. $(C)$ Single sperm, with (+) or without (-) mt nucleoids, were selectively extracted from fertilized eggs by using optical tweezers, and were analyzed by nested PCR. In this experiment, the sperm and eggs were derived from $A A 2$, and $10^{-8} \mathrm{nmol}$ of the HNI PCR product was added to each reaction as an internal control. (Nishimura et al. 2006) 


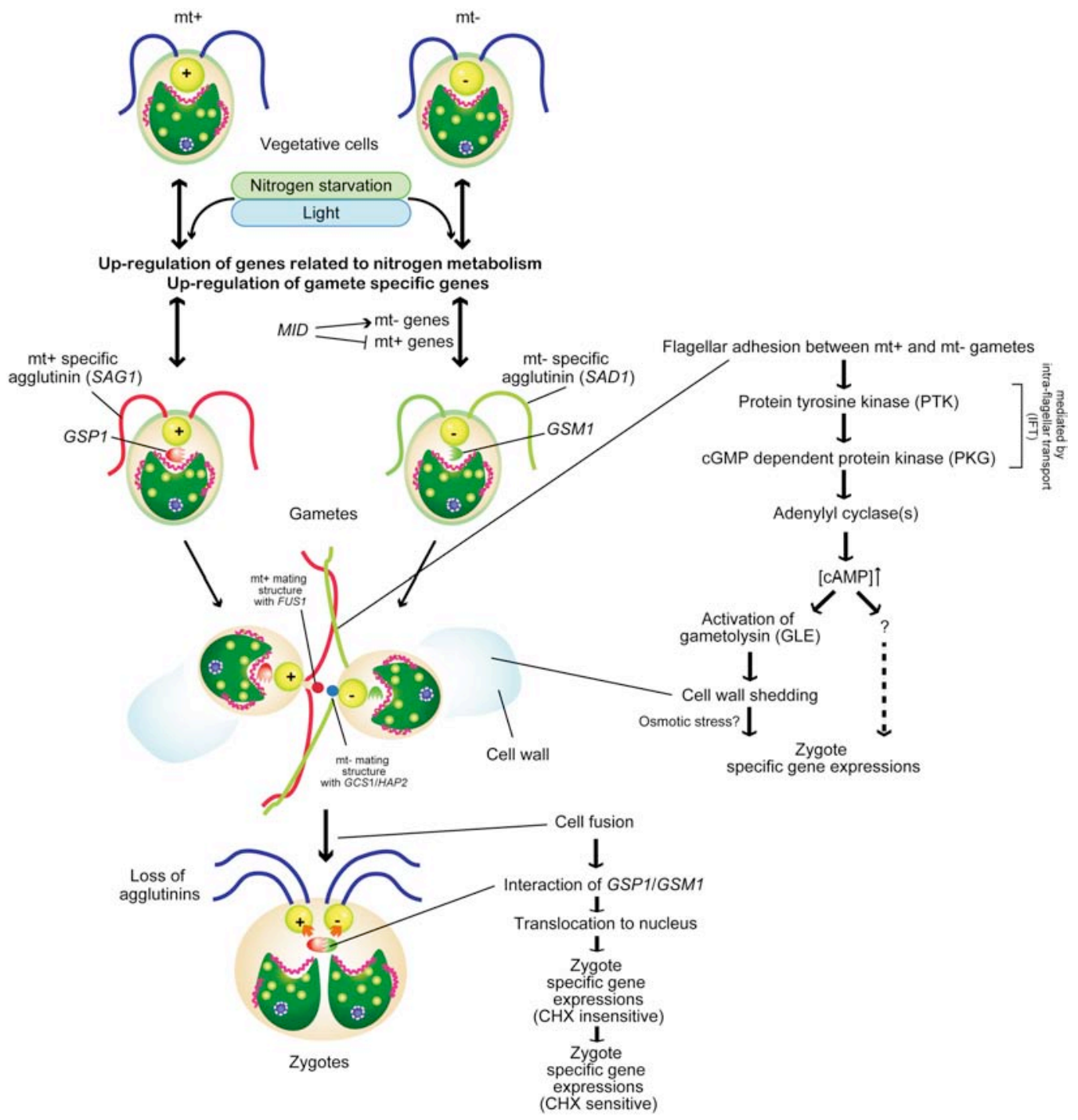

\section{Fig. 8}

The gametogenesis, mating, and zygote maturation in C. reinhardtii.

Nitrogen starvation and light signals induce vegetative cells to differentiate into $\mathrm{mt}+$ and mt- gametes, controlled by the two mating type loci (+ and -).

Upon mixing, agglutinins mediate flagellar adhesion. A rapid increase in cAMP triggers cell wall loss and activation of mating structures. Activated mating structures fuse to form zygotes, allowing the formation of the GSP1/GSM1 heterodimer, which subsequently translocates into nuclei and switches on the zygote program. 